\title{
Laboratory analysis of the main properties and a color stability of a coating layers under the UV loading
}

\author{
Petr Kulhavý ${ }^{1, a}$, Eva Kaniová ${ }^{2}$, Vítězslav Fliegel ${ }^{1}$ and Michal Vik ${ }^{2}$ \\ ${ }^{1}$ Technical University of Liberec, Dept. of Design of Machine Elements and Mechanisms, Studentská 2, 461 17, Liberec 1, \\ Czech Rep. \\ ${ }^{2}$ Technical University of Liberec, Dept. of Material Engineering, Studentská 2, 461 17, Liberec 1, Czech Rep.
}

\begin{abstract}
For individual components as well as for the final products is need to determine their resistance and other mechanical properties, which can be changing due to the various conditions and simultaneously we try to get still closer to the real operating conditions.Currently, given the need to guarantee a perfect quality of the product throughout its entire life cycle, it is necessary to assess the protective layers that are in direct contact with the material itself or with the future products. This article presents the results of testing individual components of the selected materials and their resistance to the UV rays. These were some samples of a prelacquered sheet and a powder coated plate after their forming, next by pigment colored concrete cubes, artificial wood and a prototype sample of the translucent material Licrete. Compared to a conventional climate tests such as heat, cold, humidity or the salt chambers, the colored protection layers were subjected to a strong UV rays. Subsequently was evaluated the change of the colors, brightness and where it was possible also the adhesion parameters and thickness of the coated layer. The measurement wasn't focused only on the adhesion and color stability, but also to a violation of microstructure due to high temperatures caused by the UV ray. The selected specimens were tested in a device which simulates solar radiation and then were them evaluated the changes of a colors and on the surface structure.
\end{abstract}

\section{Introduction}

Nowadays it is a considerable emphasis on to the appearance and reliable protective function of the surface layers placed on various ground materials. When choosing surface treatment and its subsequent application, we give into account the technological characteristics of the materials and also the characteristics of the used paints. Almost all of the products are always enclosed by the surface that is in contact with an ambient environment. Therefore is still there a continual mutual contact of metallic, non-metallic, liquid or the gaseous phases. Quite commonly for each of constructional materials we are looking for to its physical and mechanical properties with respect to the real mechanical and climatic loads. In the case of colored surface layers there are generally two aspects. Primarily we evaluate their properties such as the adhesion, abrasion resistance, heat resistance, chemical resistance etc. The second aspect to that we need to focus is an assessment of the surfaces exposed to the UV radiation and significance of its effect to the other parameters. The tested materials were a standard steel sheet and pre-lacquered steel plate Myriatouch. The used colored powders were from the manufacturer Sava trade and the manufacturer Beton Brož provided the prototype of concrete parts.

\section{The surface layers}

Surface treatments are primarily used for two reasons. It is an economic aspect, when we try to avoid or a significantly slow down the process of depreciation of the parts or components and also prolongs their life cycle. The second aspect could be aesthetic, when the surface finish itself, used color and their properties or processing may become the one of the pillars on which is built the sale of the final product. The surface of material generally represents the interface on which is the gradient of the electrostatic potential associated with the charge a layer and there are some changing of a chemicals concentration. Due to an unbalance of the energy field on the surface of materials arises mainly for a metallic materials top surface tension and surface energy (the most densely occupied crystalline planes with the smallest surface energy). These physicochemical events have results in a gradual or complete disturbance of the surface layers. This process gradually affects almost all construction materials.

\subsection{The tested materials}

For a testing the surface structure and a color fastness of the materials were chosen samples made of steel,

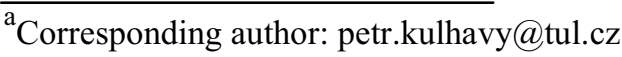


aluminum and concrete. Two types of sheet metal parts (thickness $1 \mathrm{~mm}$ ) that have been created by a two different coating procedures.

The first sample was already pre-lacquered by supplier and under the protection film it has gone through the whole production cycle, while the second sample was powdered by epoxy just after the complete machining. The other tested samples were a concrete cubes with a by pigments tinted surface layers. Made from concrete is also an imitation of wood and the prototype of translucent material Licrete. The last samples are with various methods anodized aluminum profiles.

\subsubsection{Steel}

Two used types of steel samples were in colors white RAL 9010 and black RAL 9005. The used powder paint CPC-41-1 was a smooth semi-gloss, recommended for interior, from a series of hybrid powder coatings based on polyester-modified with epoxy resins. Polyester powder coatings are generally applied for high-gloss applications, or also where the UV stability (weather resistance) is needed. In Fig. 1 there is the distribution function of the used powder coat particles size. The value of the distribution function indicates show probability that the particles are smaller than the given size.

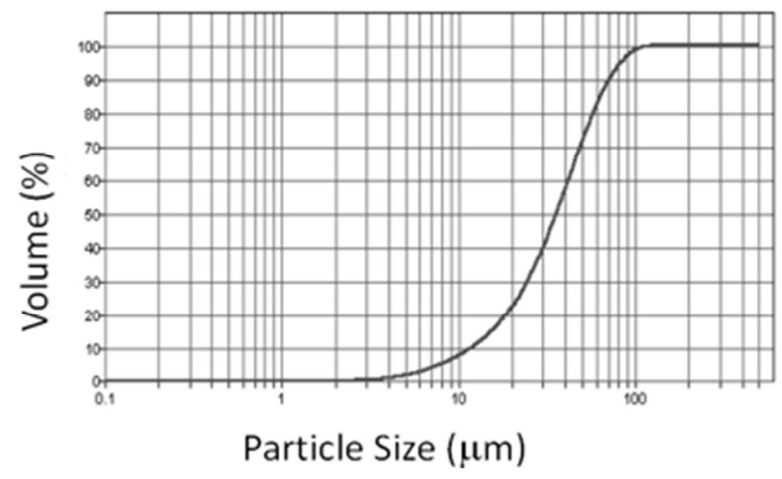

Figure 1. Particle sie distribution [1]

\subsubsection{Concrete parts}

For concrete components were used two samples. On the pigmented surface layers of the concrete cubes is controlled the surface color stability and for material Licrete (Fig.2) the rated luminous properties of the

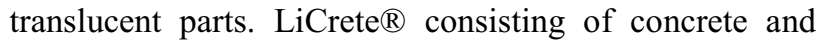
transparent elements that serve as a internal light guide.

These were simultaneously occasion to check whether the action of UV worsens the translucent parameters and also eventually disrupt connections of the interfaces the two materials due to thermal expansion.

\subsubsection{Anodized aluminum}

These layers has been typically used for two reasons, the first is the possibility of industrial shading in an almost unlimited range of colors.

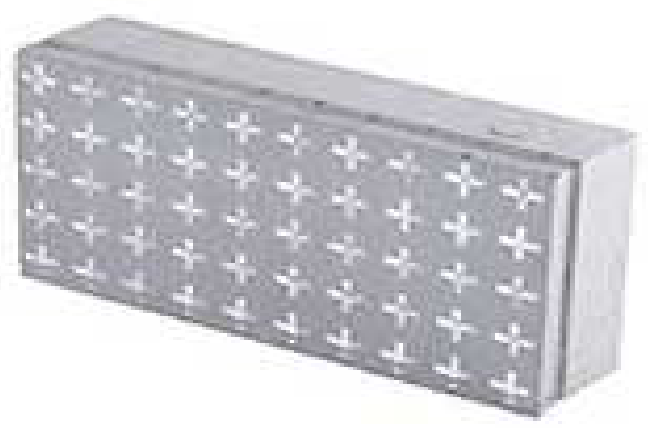

Figure 2.The translucent concrete "Licrete"

The second advantage is the resulting hard oxide layer of material surfaces, which provides better mechanical properties and chemical resistance. The thickness of the layers is usually in the range $5-20 \mu \mathrm{m}$. The tested color tones were Champagne (metal part in down section of Fig.3) and Silver (Fig.3 no.I standard, no. II sandblasted).

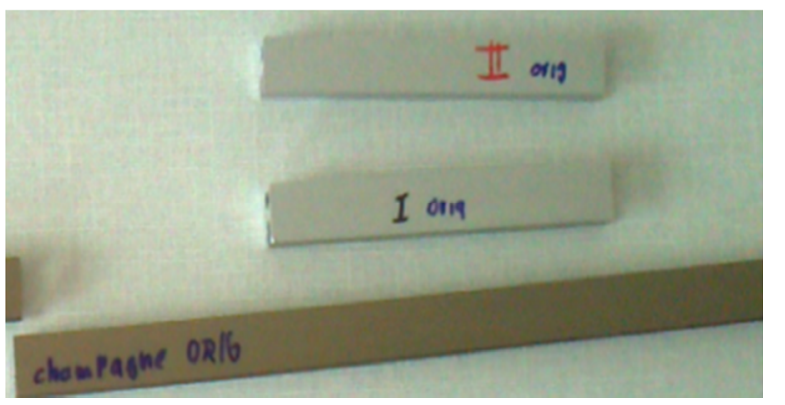

Figure 3. Aluminum profiles

\subsection{The possibility of testingthe surface layers}

For concrete materials are used primarily some typical tests according to internal standards of their manufacturers with regard to their specific application. For the anodized material is the test focused on the optical surface inspection, or it is also possible to check the closing of the pores on the layers with a hydroxide or acid.In contrast, for a metallic materials coated with powder paint we have by the standard [2] established tests:

- The electrical inductive measuring of the layer film thickness according to CSN EN ISO 2808, where some chosen individual points on the surface of the product defining the thickness of the surface layer [3].

- Macro images, visual tests used to detection defects under the surface, impurities, bubbles or cracks typically generated in response to the thermal expansion usually in a wrought locations.

- Adhesion tests of the surface layer, where is currently the one of the most popular called: Grid test of the paint adhesion. The principle of the test is to carve into the coating grid, which is, consists from orthogonal slices. 
Each of the individual slices must pass through the paint to the surface of the main material.Then is the cutting line cleaned by brush and attached with the special adhesive tape, which is subsequently torn off. The quality of the coating is evaluated according to the degree of damage of the grid during the secession of the adhesive tape. The adhesionis according to [4] rated on ascale from 0 to 5 .

\section{About the UV test}

The aim of this research was to compare the color change, resistance and other mechanical properties of coated layers exposed to operational use such as artificial light ageing in SUNTEST CPS+ device (Fig. 4).

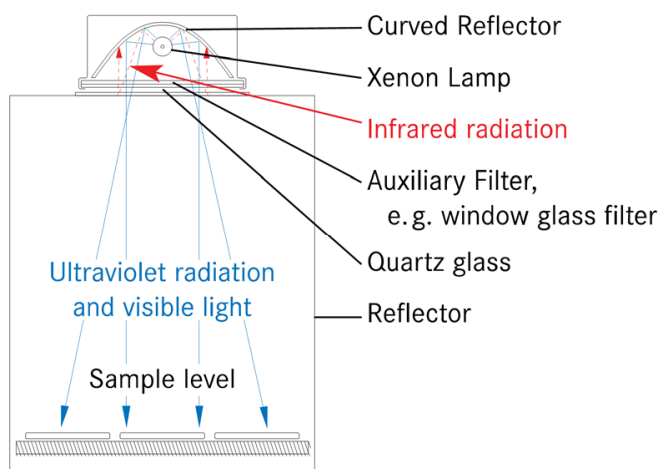

Figure 4. Test Chamber and Lighting System of SUNTEST CPS + device

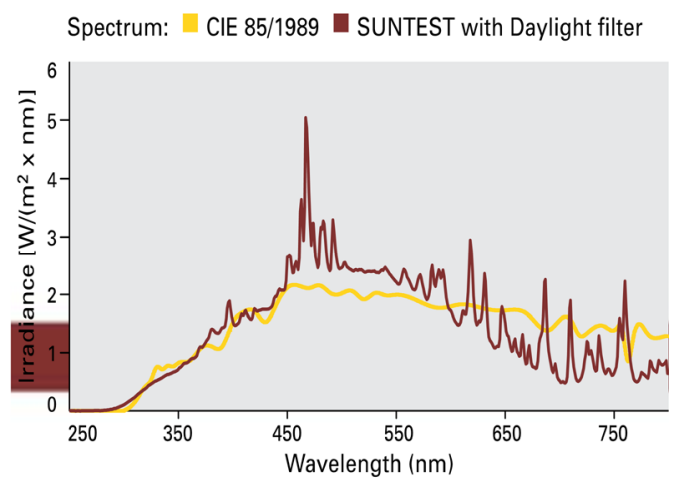

Figure 5. Composition of the used light

Artificial light ageing tests has been carried out according to ISO standard [5] in a Suntest CPS+ device. The following measuring conditions were applied:

— irradiance: $662 \mathrm{~W} / \mathrm{m}^{2}$,

- black standard temperature: $100^{\circ} \mathrm{C}$,

— daylight filter (lower limit — 290 nanometer).

The filter used allowed to simulate the solar radiation present outwards. Ten different samples were tested to light exposure for 72 hours, which is almost equal to 34 days of ageing under natural outdoor conditions and about 42 days of ageing under natural conditions prevailing indoors. The dimensions of the examined samples were different based on preparation method. After every 24-hour exposition to light in Suntest CPS+ device the papers were evaluated visually, then the optical properties were measured.

\subsection{Measurement of colorimetric properties}

The properties such as color coordinates CIELAB as well as color attributes CIE $\mathrm{LCh}_{\mathrm{ab}}$ were measured in first step under the following conditions:

- illuminant D65,

- $10^{\circ} \mathrm{CIE}$ standard observer,

— viewing condition di: $8^{\circ}$,

by Datacolor SF600+ spectrophotometer, using following tristimulus values $X Y Z(T)$ calculation:

$$
\begin{aligned}
& X=k \int_{\lambda} E_{\lambda} R_{\lambda} \bar{x}_{\lambda} d \lambda \\
& Y=k \int_{\lambda} E_{\lambda} R_{\lambda} \bar{y}_{\lambda} d \lambda \\
& Z=k \int_{\lambda} E_{\lambda} R_{\lambda} \bar{z}_{\lambda} d \lambda \\
& k=100 / \int_{\lambda} E_{\lambda} \bar{y}_{\lambda} d \lambda
\end{aligned}
$$

from which were computed $\mathrm{L}^{*} \mathrm{a} * \mathrm{~b} *$ values in case of ratios of tristimulus values $\left(T / T_{0}\right)>0.008856$ :

$$
\begin{aligned}
& L^{*}=116 \sqrt[3]{\left(\frac{Y}{Y_{0}}\right)}-16 \\
& a^{*}=500\left[\sqrt[3]{\left(\frac{X}{X_{0}}\right)}-\sqrt[3]{\left(\frac{Y}{Y_{0}}\right)}\right] \\
& b^{*}=200\left[\sqrt[3]{\left(\frac{Y}{Y_{0}}\right)}-\sqrt[3]{\left(\frac{Z}{Z_{0}}\right)}\right]
\end{aligned}
$$

Where: $T_{0}$ are tristimulus values of perfect reflecting diffuser at used illuminant (D65: $X=94.811 ; Y=100$ and $Z=107.305)$. In other cases, when ratio of tristimulus values is less or equal then 0.008856 , are used linear transformation functions [6].

The $\mathrm{L}^{*} \mathrm{a}{ }^{*} \mathrm{~b}^{*}$ system is also referred to as the CIELAB system. It can be visualized as a cylindrical coordinate system in which the axis of the cylinder is the lightness variable $L^{*}$, ranging from 0 to 100 , the radius is the chromaticity variable $C^{*}$, and hue angle $h^{\circ}$ :

$$
\begin{gathered}
C^{*}=\sqrt{\left(a^{*}\right)^{2}+\left(b^{*}\right)^{2}} \\
h^{\circ}=\arctan \left(\frac{b^{*}}{a^{*}}\right) \text { in degrees }\left(0-360^{\circ}\right)
\end{gathered}
$$

As third step was calculated color difference $\Delta \mathrm{E}^{*}$ between specimen data after and before exposure: 


$$
\Delta E^{*}=\sqrt{(\Delta L *)^{2}+\left(\Delta a^{*}\right)^{2}+\left(\Delta b^{*}\right)^{2}}
$$

Due to high roughness of some samples was used substantial method based on non-contact measurement. Each sample was firstly captured by digital camera CANON EOS300D in viewing box SPL III (X-Rite) under daylight simulator D65 and viewing conditions $45^{\circ} \mathrm{x}: 0^{\circ}$ together with 24 color standards of X-Rite ColorChecker (CC24) as visible on Fig. 6:

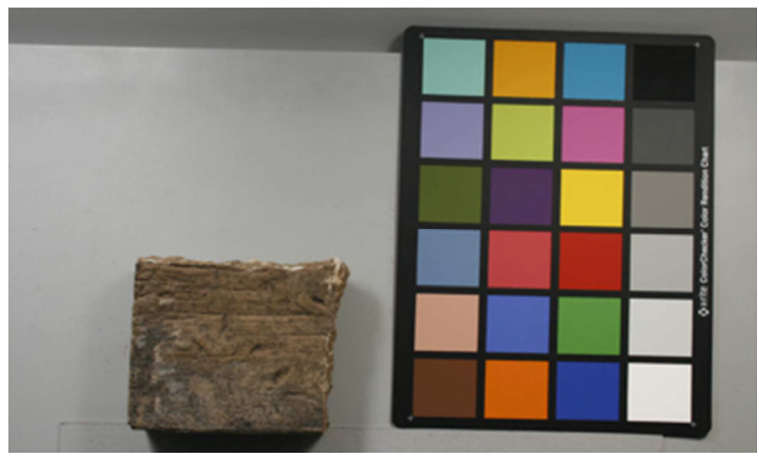

Figure 6. Image of the concrete sample with $\mathrm{CC} 24$

As last step of this procedure were measured RGB values of pixels relating to sample and color standard CC24, which were transformed into XYZ values via the following transformation matrix $\mathbf{B}$ computed from known tristimulus values of $\mathrm{CC} 24$ color standard by optimization procedure:

$$
\left(\begin{array}{c}
X \\
Y \\
Z
\end{array}\right)=B^{-1}\left(\begin{array}{c}
R \\
G \\
B
\end{array}\right)
$$

\section{Test results}

A visual evaluation showed that after third cycle of exposure are visible color differences between samples on the start and the end of experiment and for people with superior color discrimination for all of the tested samples. All observers agreed that most visible difference was assessed for sample imitating wood.

Due to the mentioned problems with contact measurement of color coordinates by spectrophotometer are there presented only color coordinates based on noncontact measurement. Tab. 1 and Tab. 2 shows $L^{*} a^{*} b^{*}$ of the samples before exposure to UV light and after 72 hour of exposure.

Table 1. Color coordinates before exposure (on the start)

\begin{tabular}{|l|c|c|c|c|c|c|}
\hline \multirow{2}{*}{\multicolumn{1}{c|}{ Sample }} & \multicolumn{7}{c|}{ unexposed } \\
\cline { 2 - 7 } & $L^{*}$ & $a^{*}$ & $b^{*}$ & $C^{*} a b$ & hrad & hab \\
\hline Steel RAL 9005 černý & 24.68 & 0.13 & -0.43 & 0.45 & 5.00 & 286.73 \\
\hline Steel Ral 9010 bílý & 93.57 & -0.72 & 4.54 & 4.60 & 1.73 & 98.99 \\
\hline Imitation of the wood & 67.45 & 1.05 & 12.77 & 12.81 & 1.49 & 85.32 \\
\hline Licrete (concrete) & 82.62 & -1.37 & 7.32 & 7.45 & 1.76 & 100.57 \\
\hline Al Champagne & 67.46 & 1.08 & 12.89 & 12.94 & 1.49 & 85.22 \\
\hline Al Silver & 85.66 & -0.86 & 1.52 & 1.75 & 2.08 & 119.43 \\
\hline Al Silver Corado & 86.36 & -1.03 & 1.06 & 1.48 & 2.34 & 134.36 \\
\hline Concrete cube red & 62.73 & 10.41 & 14.49 & 17.84 & 0.95 & 54.30 \\
\hline Concrete cube yellow & 67.55 & 6.77 & 26.87 & 27.71 & 1.32 & 75.86 \\
\hline
\end{tabular}

Table 2. Color coordinates after 72-hour exposure

\begin{tabular}{|c|c|c|c|c|c|}
\hline \multicolumn{7}{|c|}{ exposed } \\
\hline$L^{*}$ & $a^{*}$ & $b^{*}$ & $C^{*} a b$ & hrad & $h a b$ \\
\hline 25.23 & 0.10 & -0.63 & 0.64 & 4.87 & 279.21 \\
\hline 93.05 & -1.05 & 4.67 & 4.78 & 1.79 & 102.73 \\
\hline 60.74 & 5.06 & 11.48 & 12.55 & 1.16 & 66.23 \\
\hline 86.55 & -1.44 & 5.55 & 5.73 & 1.82 & 104.51 \\
\hline 64.90 & 1.26 & 14.41 & 14.47 & 1.48 & 85.00 \\
\hline 85.81 & -0.94 & 0.93 & 1.32 & 2.36 & 135.16 \\
\hline 86.82 & -1.06 & 0.43 & 1.15 & 2.76 & 158.21 \\
\hline 59.29 & 12.30 & 15.37 & 19.68 & 0.90 & 51.33 \\
\hline 72.69 & 6.92 & 28.49 & 29.32 & 1.33 & 76.35 \\
\hline
\end{tabular}

Color differences between samples on the start and on the end after third cycle of exposure are represented in Tab. 3 together with graph on figure 7 , where is visible effect of light exposure on differences in individual coordinates.

Table 3. Color differences after 72-hour exposure

\begin{tabular}{|c|c|c|c|c|c|}
\hline \multicolumn{7}{|c|}{ difference } \\
\hline$d L^{*}$ & $d a^{*}$ & $d b^{*}$ & $d C^{*}$ & $d H 76$ & $d E^{*}$ \\
\hline 0.55 & -0.03 & -0.21 & 0.20 & -0.07 & 0.59 \\
\hline-0.53 & -0.34 & 0.12 & 0.19 & 0.31 & 0.64 \\
\hline-6.71 & 4.01 & -1.28 & -0.26 & -4.20 & 7.93 \\
\hline 3.93 & -0.07 & -1.77 & -1.71 & 0.45 & 4.31 \\
\hline-2.56 & 0.18 & 1.52 & 1.53 & -0.05 & 2.98 \\
\hline 0.15 & -0.08 & -0.59 & -0.43 & 0.42 & 0.61 \\
\hline 0.47 & -0.03 & -0.63 & -0.33 & 0.54 & 0.79 \\
\hline-3.44 & 1.89 & 0.88 & 1.85 & -0.97 & 4.02 \\
\hline 5.13 & 0.15 & 1.62 & 1.60 & 0.24 & 5.38 \\
\hline
\end{tabular}

Graph on the figure 7 show that samples with measured high color difference (above 4 units) are affected by change in lightness $L^{*}$, where only concrete samples show increasing of this value. In other cases was visible decreasing of lightness value. This effect is mainly caused by increasing of roughness of tested samples as visible on picture in figure 10 .

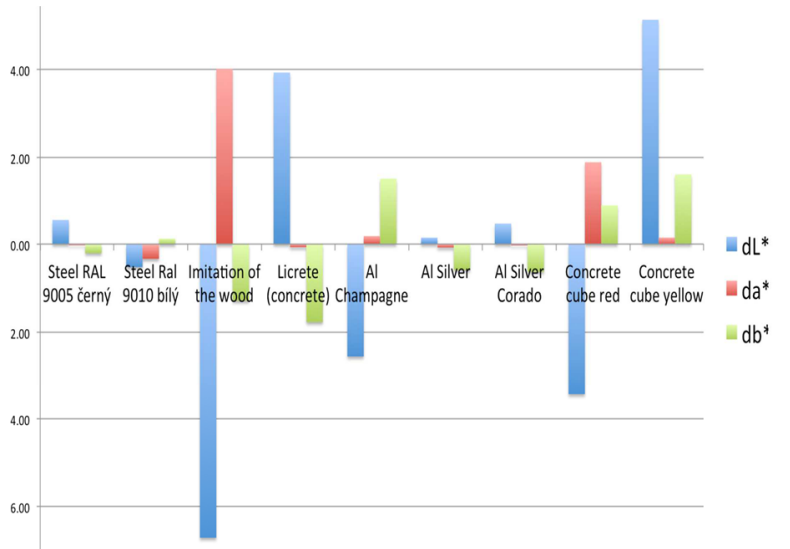

Figure 7. Vectors visualization of color changes

Beside effect of exposure on lightness values as second most visible effect is found for color coordinate $b^{*}$, which is the blue (negative) to yellow (positive) axis. There are only two exceptions for sample imitating wood and concrete cube red, where is visible color change measured in color coordinate $a^{*}$, which is the green 
(negative) to red (positive) axis. It is interesting; that in both situations measured effect was positive color change, because expecting effect is decreasing of chromacity, which means sample after exposure is obviously duller than on the start. Possible explanation of this result is artificial simulation of sunlight exposure, which is in natural conditions obviously followed by dust exposure. Such improvement of test procedure is now prepared as continuous research in weathering testing of materials used in civil engineering.

In figure 8 are visible color differences on the chromatic plane of CIELAB color space, where are showed samples before (circle) and after third cycle of exposure (triangle).

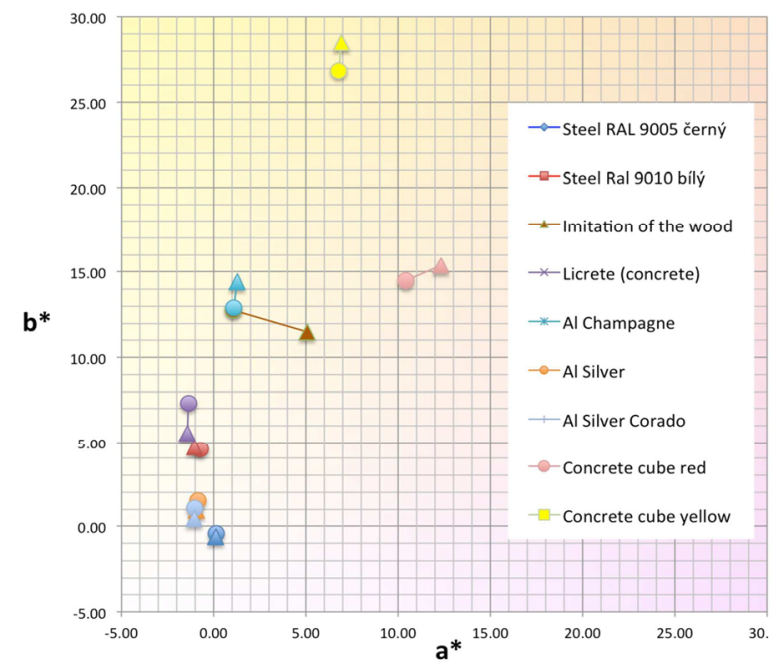

Figure 8. Vectors visualization of color changes

\section{Measurement of physical properties}

For the concrete materials the fundamental to us is primarily the color stability of the pigment layers. For painted and anodized parts components is need to consider some more properties. This is an assessment of the effect of UV radiation to the structure, thickness of lacquer layer, surface quality and possibly also changes in the adhesion properties.

\subsection{Determination of the dry film thickness}

Using the device Salutroncombi D3M has been carried out measuring of the thickness of the surface layer. This device works generally on the principle to receiving electromagnetic waves reflected from the metal surface. For materials based on $\mathrm{Fe}$ is used anelectromagnetic induction and for the non-ferrous and nonconductive materials are used whirlpool currents.

The device used for measuring the thickness of the layer is before measuring inspected and calibrated with using an etalon foil. The layer is always measured at several points of the product, ideally in the middle and on the edge regions if it is possible. Simultaneously are evaluated some frequently occurring defects under the surface. Typically impurities, air bubbles or cracks caused generally in response to the thermal dilatations

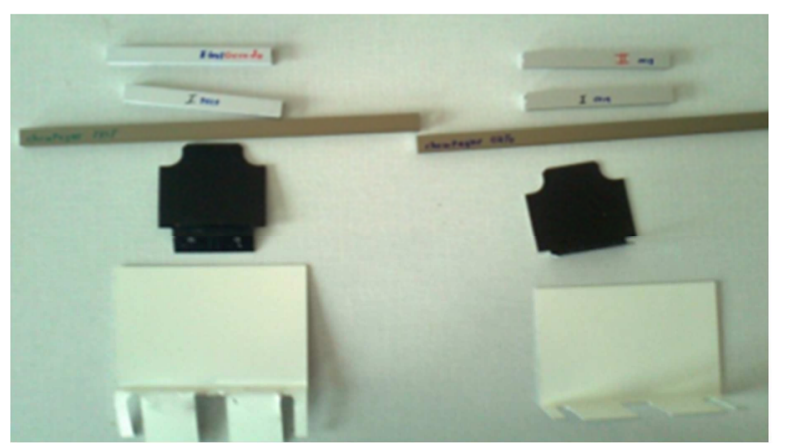

Figure 9. Measured Fe and NonFe parts

Table 4. Thickness of the coat layer $(\mu \mathrm{m})$

\begin{tabular}{|l|c|c|c|c|}
\hline & \multicolumn{2}{|c|}{ Unexposed } & \multicolumn{2}{c|}{ Exposed } \\
\cline { 2 - 5 } & Mean value & St. deviation & Mean value & St. deviation \\
\hline Pre-lacquered sheet & 45,5 & 2,94 & 42,1 & 4,04 \\
\hline Powder coated sheet & 50,1 & 2,9 & 52 & 5,04 \\
\hline AL Champaine & 18,1 & 2,67 & 21,25 & 2,9 \\
\hline AL Silver & 19,7 & 1,82 & 22,15 & 0,68 \\
\hline AL Silver Corado & 18,5 & 4,34 & 16,2 & 1,7 \\
\hline
\end{tabular}

Due to big differences of the thickness of each part, it's not possible to accurately assess the potential influencing of the UV ray. Therefore according to Tab. 4 there can't be observed a provable influence to the resultant thickness of the layer.

\subsection{Grid test of the paint adhesion}

On all powder coated parts, was also carried the most important test, indicating the value of adhesion. Into a series of samples were before and after illumination with using the standardized incisor cut grid (Fig.10) from which was subsequently pulled down the special adhesive ISO tape. After the tearing of the tape has been under zooming evaluated the resulting deformation and vacancies of the grid.

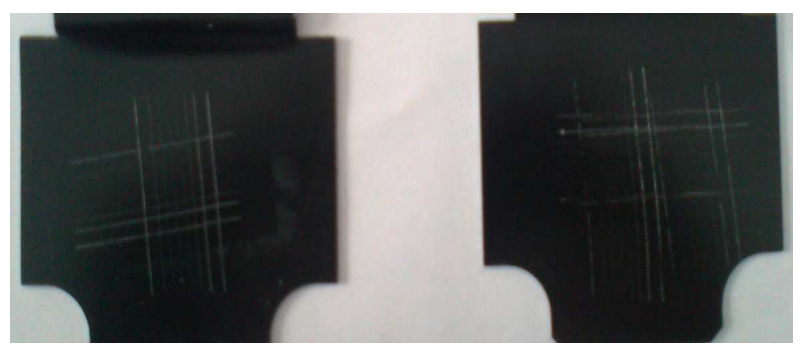

Figure 10. The grid after application of the adhesive tape

\subsection{Macro-surface structure}

Due to thermal dilatation, especially in the case of materials combined of several elements, it was necessary to assess also their macrostructure. The structure is usually evaluated by the microcamera under good 
lighting conditions. In case of finding defects there are typically the cracks, bubbles or separation between phases. On the measured samples any similar cases has not been detected. It can be stated that the UV ray and temperatures around $100{ }^{\circ} \mathrm{C}$ don't threaten the surfaces.

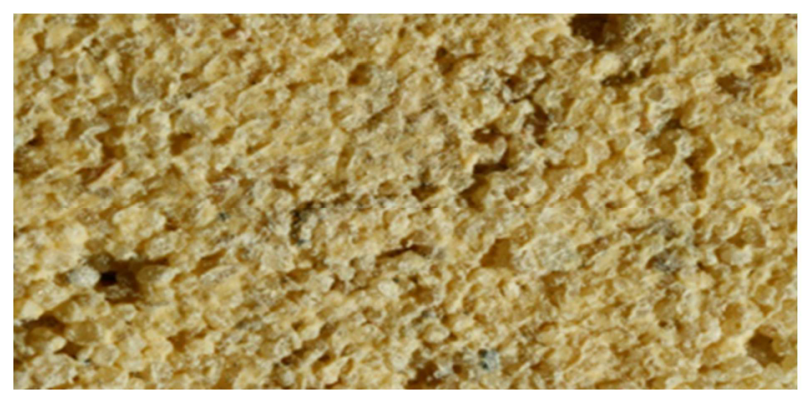

Figure 11. An example of the microstructure

\section{Conclusion}

We can say that there hasn't been found any demonstrable influence of the UV rays or the simultaneously generated heat to any of the observed mechanically measurable parameters. It has been found out that the only changes were in the tones and the brightness of the colors coating on the surfaces. Recognize the color change with the naked eye, it was possible only for one of the materials, namely the white powder coated steel. Find the differences in the other cases were possible only with using a specific computer optical viewing technology.

\section{Acknowledgements}

This work was supported by the project TKMOST.

\section{References}

1. Technical data sheets of the specialized powder coatings manufacturer Sava trade ltd.

2. ČSN EN ISO 4287. Geometrické požadavky na výrobky (GPS) - Struktura povrchu: Profilová metoda. Terminy, definice a parametry struktury povrchu.Praha: Český normalizační institut, 1999.

3. ČSN EN ISO 2808. Nátérové hmoty - Stanovení tloušt'ky nátěru. Praha: Český normalizační institut, 2000.

4. ČSN ISO 2409. Nátěrové hmoty - Mřížková zkouška. Praha: Úřad pro normalizaci aměření, 1992.

5. ISO 11341:2004: Paints and varnishes - artificial weathering and exposure to artificial radiation exposure to filtered xenon-arc radiation.

6. CIE 15:2004 Colorimetry

7. MAZUREK, Pavel. Práškové barvy a jejich odlupování. MM Průmyslovéspektrum. 2005.

8. MAHMOUD, Manal G. Influence of ultraviolet light irradiation on corrosion behavior of weathering steel. Scripta Materialia. 2005, vol. 53, DOI: 10.1016/j.scriptamat.2005.07.039.

9. http://www.casopis-koroze.cz/index.php 